\title{
PERSEPSI MAHASISWA TENTANG PERATURAN BERBUSANA KE KAMPUS DI JURUSAN ILMU KESEJAHTERAAN KELUARGA FAKULTAS PARIWISATA DAN PERHOTELAN UNIVERSITAS NEGERI PADANG
}

\author{
Intan Sri Honesti ${ }^{1}$, Ernawati ${ }^{2}$ \\ Program Studi Pendidikan Kesejahteraan Keluarga \\ Jurusan Ilmu Kesejahteraan Keluarga \\ Fakultas Pariwisata dan Perhotelan, Universitas Negeri Padang \\ Email : srihonestiintan@gmail.com \\ Published: 2019-12-31 \\ DOI: https://doi.org/10.24036/ipk/vol11-iss1/641 \\ URL: http://jpk.ppj.unp.ac.id/index.php/jpk/article/view/641
}

Submitted: 2019-08-08 Accepted: 2019-10-29

\begin{abstract}
This research is motivated by the lack of awareness of the students of the Department of Family Welfare in the Faculty of Tourism and Hospitality, Padang State University in obeying the rules of dress that have been set. The purpose of this study is to describe how students' perceptions about the rules of dressing to the campus in the Department of Family Welfare Science Faculty of Tourism and Hospitality, Padang State University. The methodology used in this research is quantitative descriptive. The study population was students of the Family Welfare Education Department of Family Welfare Sciences, Faculty of Tourism and Hospitality, Padang State University class of 2012 - 2017 who registered in the January-June 2019 semester of 487 people. The research sample of 100 people with the sampling technique is proportional random sampling. Data collection techniques using a questionnaire. The data analysis technique used SPSS 16. The results showed that students' perceptions about the rules of dressing on campus were in the excellent category at $90.26 \%$. This means students perceive that students in dressing to the campus are in accordance with the regulations that have been applied by the Department of Family Welfare of the Faculty of Tourism and Hospitality, Padang State University.
\end{abstract}

Keywords: perception, dress code

\begin{abstract}
Abstrak
Penelitian ini di latar belakangi karena kurangnya kesadaran mahasiswa Jurusan Ilmu Kesejahteraan Keluarga Fakultas Pariwisata dan Perhotelan Universitas Negeri Padang dalam mentaati peraturan berbusana yang telah di tetapkan. Tujuan penelitian ini adalah untuk mendeskripsikan bagaimana persepsi mahasiswa tentang peraturan berbusana ke kampus di Jurusan Ilmu Kesejahteraan Keluarga Fakultas Pariwisata dan Perhotelan Universitas Negeri Padang . Metodologi yang digunakan dalam penelitian ini adalah deskriptif kuantitatif. Populasi penelitian adalah mahasiswa Pendidikan Kesejahteraaan Keluarga Jurusan Ilmu Kesejahteraan Keluarga Fakultas Pariwisata dan Perhotelan Universitas Negeri Padang angkatan 2012 - 2017
\end{abstract}

This is an open access article distributed under the Creative Commons 4.0 Attribution License, which permits unrestricted use, distribution, and reproduction in any medium, provided the original work is properly cited. $\odot 2017$ by author and Universitas Negeri Padang. 
yang terdaftar pada semester Januari - Juni 2019 sebanyak 487 orang. Sampel penelitian berjumlah 100 orang dengan teknik pengambilan sampel adalah proportional random sampling. Teknik pengumpulan data menggunakan angket. Teknik analisis data menggunakan SPSS 16. hasil penelitian menunjukkan persepsi mahasiswa tentang peraturan berbusana ke kampus berada pada kategori sangat baik yaitu 90,26\%. Hal ini berarti mahasiswa berpersepsi bahwa mahasiswa dalam berbusana ke kampus telah sesuai dengan peraturan yang telah di terapkan oleh Jurusan Ilmu Kesejahteraan Keluarga Fakultas Pariwisata dan Perhotelan Universitas Negeri Padang.

Kata kunci: persepsi, peraturan berbusana

\section{Pendahuluan}

Kebutuhan manusia akan busana timbul dari dalam nalurinya untuk menghias diri dan melindungi tubuh, serta rasa kesusilaan. Penampilan terutama dalam berbusana menjadi sesuatu hal yang penting dalam merias tubuh untuk melibatkan identitas diri. Dari penampilan, orang lain bisa melihat bagaimana orang tersebut, karena penampilan juga mencerminkan pribadi seseorang. Berbusana pada setiap kesempatan perlu memperhatikan etika serta peraturan- peraturan yang berlaku seperti halnya berbusana pada kesempatan ke kampus. Aturan itu sendiri adalah tataan (petunjuk, kaidah, ketentuan) yang dibuat untuk mengatur. Peraturan juga dapat di artikan dengan tata tertib. Menurut Rifa'I (2011: 139) tata tertib adalah kumpulan aturan - aturan yang di buat secara tertulis dan mengikat anggota masyarakat. Jika di kait kan dengan aturan berbusana adalah suatu ketentuan yang di buat untuk mengatur dalam hal berbusana sehingga dalam hal berbusana kita tidak bisa sembarangan dalam menggunakannya karena di setiap kesempatan ada etika dan aturan yang berlaku.

Berbusana ke kampus berbeda dengan berbusana sewaktu masih belajar di SLTA. Di perguruan tinggi mahasiswa tidak terlalu terikat pada pakaian seragam (uniform), kecuali ada kesepakatan di tingkat mahasiswa dan jurusan. Universitas Negeri Padang merupakan salah satu Universitas Negeri di Indonesia memiliki aturan bagi mahasiswa dalam berbusana ke kampus sesuai dengan buku peraturan akademik UNP 2015 pasal 12 bahwa "Setiap mahasiswa memiliki kewajiban berpakaian rapi dan sopan sesuai dengan nilai-nilai dan norma yang berlaku dalam mengikuti proses pembelajaran dan di lingkungan kampus."

Selain buku peraturan akademik peraturan berbusana di UNP juga di jelaskan didalam kode etik mahasiswa, sesuai dengan keputusan rektor Universitas Negeri Padang No: 146/H35/KP/2004 yang menjelaskan di antaranya "Mahasiswa UNP wajib berpakaian sopan dan rapi, tidak memakai sandal dan celana pendek di lingkungan kampus.

Berdasarkan apa yang di jelaskan di atas merupakan peraturan berbusana secara umum bagi seluruh mahasiswa di Universitas Negeri Padang. Aturan berbusana di UNP sudah di jelaskan ke kapada mahasiswa ketika awal masuk UNP yaitu pada kegiatan pengenalan kehidupan kampus bagi mahasiswa baru (PKKMB). Pada kegiatan PKKMB mahasiswa di beri materi apa-apa saya yang berkaitan dengan ke hidupan kampus termasuk salah satunya aturan dalam berbusana baik itu ketika mengikuti perkuliahan ataupun berada di lingkungan kampus.

Peraturan perbusana bagi mahasiswa UNP juga di atur oleh setiap jurusan salah satunya Jurusan IKK FPP UNP yang membuat aturan berbusana bagi mahasiswa Jurusan IKK FPP UNP. Aturan tersebut tertuang di dalam kontak perkuliahan berbunyi "Mahasiswa harus berpakaian rapi, memakai sepatu, berambut pendek, dan tidak menggunakan aksesoris bagi laki- laki Bagi mahasiswa yang berpakaian tidak sesuai 
dengan aturan, tidak di benarkan mengikuti perkuliahan dan yang bersangkutan di anggap tidak hadir".

Sehubungan dengan peraturan yang telah di tetapkan maka mahasiswa memiliki persepsi yang berbeda dalam berbusana ke kampus. Menurut Ahmad (1996:28) "Persepsi berarti tanggapan atau menanggapi." sedangkan menurut Ruhimat (2012:52) Persepsi merupakan kemampuan seseorang dalam memandang sesuatu yang di permasalahkan.” sedangkan menurut Kotler (2004 : 193) yang menyatakan bahwa persepsi merupakan suatu proses di mana seseorang dapat memilih, mengatur, dan mengartikan informasi menjadi suatu gambar yang sangat berarti di dunia.

Persepsi mahasiswa tentang aturan berbusana ke kampus di Jurusan IKK FPP UNP terlihat dari cara berbusana mahasiswa ke kampus ada yang mentaati peraturan yang telah di tetapkan dan masih ada juga mahasiswa yang melanggar peraturan yang telah di tetapkan.Bagi mahasiwa yang melanggar peraturan berbusana ke kampus belum di terima oleh mahasiswa sesuai dengan apa yang telah di tetapkan. Adapun tujuan penelitian ini adalah untuk mendeskripsikan persepsi mahasiswa tentang peraturan berbusana ke kampus di Jurusan Ilmu Kesejahteraan Keluarga Fakultas Pariwisata dan Perhotelan Universitas Negeri Padang.

\section{Metode Penelitian}

Jenis penelitian adalah deskriptif kuantitatif. Populasi dalam penelitian ini yaitu mahasiswa PKK Jurusan IKK FPP UNP angkatan 2012 - 2017 yang terdaftar pada semester Januari - Juni 2019 yang berjumlah 487 orang. Teknik pengambilan sampel menggunakan proportional random sampling dengan jumlah sampel 100 orang. Pengumpulan data menggunakan angket dan di analisis menggunakan program SPSS 16.

\section{Hasil Dan Pembahasan}

\section{Hasil}

Sesuai dengan penelitian mengenai persepsi mahasiswa terhadap peraturan berbusana ke kampus mahasiswa Jurusan IKK FPP UNP yang di kumpulkan melalui angket atau koesioner yang di sebarkan kepada 100 orang responden penelitian, dan setiap jawaban responden diolah dengan menggunakan program SPSS versi 16.00 maka di dapat hasil sebagai berikut:

Tabel 1. Deskripsi Data Tentang Peraturan Berbusana Ke kampus

\begin{tabular}{lll}
\hline $\mathrm{N}$ & Valid & 100 \\
\cline { 2 - 3 } & Missing & 0 \\
\hline Mean & 57.7700 \\
\hline Median & 59.0000 \\
\hline Mode & 59.00 \\
\hline Std. Deviation & 4.66852 \\
\hline Variance & 21.795 \\
\hline Range & 28.00 \\
\hline Minimum & 36.00 \\
\hline Maximum & 64.00 \\
\hline Sum & 5777.00 \\
\hline
\end{tabular}

This is an open access article distributed under the Creative Commons 4.0 Attribution License, which permits unrestricted use, distribution, and reproduction in any medium, provided the original work is properly cited. $\odot 2017$ by author and Universitas Negeri Padang. 
Dari tabel 1. di ketahui bahwa data persepsi mahasiswa terhadap peraturan berbusana ke kampus maka di peroleh skor maximum 64.00, skor minimum 36.00, nilai rata-rata 57,77, median 59.00, modus 59.00 dan Std deviation 4.66.

Gambaran distribusi frekuensi data persepsi mahasiswa tentang peraturan berbusana ke kampus dapat dilihat pada tabel di bawah ini

Tabel 2. Distribusi Frekuensi Persepsi Mahasiswa Tentang Peraturan Berbusana Ke Kampus di Jurusan IKK FPP UNP Dari 100 Responden

\begin{tabular}{lll}
\hline Kelas Interval & Frekuensi (f) & Persentase \% (p) \\
\hline $36-39$ & 2 & $2 \%$ \\
\hline $48-51$ & 5 & $5 \%$ \\
\hline $52-55$ & 15 & $15 \%$ \\
\hline $56-59$ & 40 & $40 \%$ \\
\hline $60-63$ & 32 & $32 \%$ \\
\hline $64-67$ & 6 & $6 \%$ \\
\hline Total & 100 & $100 \%$ \\
\hline
\end{tabular}

Berdasarkan data yang di peroleh di atas dapat dilihat bahwa persepsi mahasiswa terhadap peraturan berbusana ke kampus dari 100 orang responden terdapat nilai terendah 36 dan nilai tertinggi 64, frekuensi terbanyak berada pada kelas interval 56 - 59 yaitu 40 responden ( $40 \%$ ) dan frekuensi terendah berada pada kelas interval 36 - 39 yaitu 2 responden ( $2 \%$ ). Hasil analisis deskriptif, variabel peraturan berbusana ke kampus dari responden, diperoleh hasil sebagai berikut:

Tingkat pencapaian $=\frac{\text { Skor rata }- \text { rata }}{\text { Skor ideal }} \times 100 \%$

Skor ideal = banyak Item $\mathrm{x}$ opnion

$=16 \times 4=64$

Skor rata-rata $=57,77$

Tingkat pencapaian $=57,77: 64 \times 100 \%$

$=90,26 \%$

Tingkat pencapaian angket indikator persepsi mahasiswa terhadap peraturan berbusana ke kampus di peroleh tingkat pencapaian sebesar 90,26\% maka tingkat pencapaian hasil koesioner berada pada kategori sangat baik. ( pengkategorian menurut Arikunto 2003:57). Hal ini berarti mahasiswa berpersepsi bahwa mahasiswa dalam berpakaian ke kampus sudah menyesuiakan dengan aturan berbusana yang telah di tetapkan atau dengan kata lain mahasiswa telah mengikuti peraturan berbusana dalam mengikuti perkuliahan maupun di lingkungan kampus.

\section{Pembahasan}

Berdasarkan hasil analisis yang telah dilakukan, maka persepsi mahasiswa terhadap peraturan berbusana ke kampus di jurusan IKK angkatan 2012 - 2017 Fakultas Pariwisata dan Perhotelan Universitas Negeri Padang, hasil koesioner berada pada kategori sangat baik (90,26\%). Hal ini menunjukkan mahasiswa berpersepsi bahwa mahasiswa dalam berbusana ke kampus telah sesuai dengan peraturan berbusana ke kampus di Jurusan IKK FPP UNP. Hal ini di buktikan dengan mahasiswa ketika mengikuti perkuliahan dan non perkuliahan telah memakai pakaian yang rapi dan sopan.

Hasil penelitian ini sama dengan hasil penelitian yang dilakukan oleh Anna (2017) dengan judul "implementasi kode etik mahasiswa tentang disiplin berbusana (studi di fakultas tarbiyah dan keguruan)", hasil penelitian tersebut menunjukkan bahwa 90\% mahasiswa sudah mengimplementasikan kode etik berbusana yang berlaku di kampus 
dan dibuktikan dengan sejak menempati kampus II ini mayoritas mahasiswa Fakultas Tarbiyah dan Keguruan sudah mengenakan busana yang rapi dan sopan sesuai dengan kode etik.

\section{Kesimpulan dan Saran}

\section{Kesimpulan}

Persepsi mahasiswa terhadap peraturan berbusana ke kampus di Jurusan IKK FPP UNP di peroleh persentase tingkat pencapaian responden dengan kategori sangat baik sebesar $(90,26 \%)$ artinya mahasiswa berpersepsi bahwa mahasiswa dalam berbusana ke kampus telah sesuai dengan peraturan berbusana ke kampus di Jurusan IKK FPP UNP.

Saran

Mahasiswa harus mempertahankan dan mematuhi peraturan berbusana ke kampus baik itu peraturan berbusana yang ada pada kontrak perkuliahan, buku peraturan akademik maupun peraturan berbusana yang ada pada kode etik mahasiswa. Diharapkan kepada setiap ketua Prodi di Jurusan IKK FPP UNP untuk kedepannya membuat peraturan khusus bagi mahasiswa tentang berbusana ke kampus dengan di pedomani berdasrkan peraturan berbusana di Universitas.

\section{DAFTAR PUSTAKA}

Anna Amalliyah. 2017. Skripsi "Implementasi Kode Etik Mahasiswa Tentang Disiplin Berbusana (Studi di Fakultas Tarbiyah dan Keguruan)", [online] di unduh pada tanggal 25/7/2019

Achmad, Rifa'I. 2009. Psikologi Pendidikan. Semarang : UNNES PRESS

Arikunto, Suharsimi. 2003. Prosedur Penelitian, suatu Praktek. Jakarta: Bina Aksara

Depdiknas. 2001. Manajemen Peningkatan Mutu Berbasis Sekolah, Buku 1 Konsep dan Pelaksanaan. Jakarta : Dirjen Dikdasmen

Kode Etik Mahasiswa Universitas Negeri Padang NO.146/H35/KP/2004

Kotler, Philip dan Gary Armstrong. 2004. Dasar-darar Pemasaran , edisi ke sembilan, jilid 2. dialih bahasakan oleh Alexander sindoro, Jakarta: Indeks

Ruhimat, Tato, dkk. 2013. Kurikulum \& Pembelajaran. Jakarta: Raja Grafindo Perada

Universitas Negeri Padang. 2015. Buku Peraturan Akademik UNP Tahun 2015. Padang: UNP

Universitas negeri padang. 2012. Buku materi pengenalan kehidupan kampus bagi mahasiswa baru tahun 2012. Padang: UNP

Yuliananingsih. 2017. artikel "Pengaruh Pelaksanaan Kode Etik Mahasiswa Terhadap Disiplin Mahasiswa di Lingkungan Kampus IKIP PGRI Pontianak.” [online] di unduh pada tanggal 25/7/2019.

This is an open access article distributed under the Creative Commons 4.0 Attribution License, which permits unrestricted use, distribution, and reproduction in any medium, provided the original work is properly cited. (O2017 by author and Universitas Negeri Padang. 